\title{
3-Hydrogenkwadaphnin Induces Monocytic Differentiation and Enhances Retinoic Acid-mediated Granulocytic Differentiation in NB4 Cell Line
}

\author{
Mohammad Amin Moosavi ${ }^{1}$, Razieh Yazdanparast ${ }^{1, *}$ and Abbas Lotfi ${ }^{2}$ \\ ${ }^{1}$ Institute of Biochemistry and Biophysics, P. O. Box. 13145-1384 University of Tehran, Tehran, Iran \\ ${ }^{2}$ National Research Center for Genetic Engineering and Biotechnology, P. O. Box. 14155-6343 Tehran, Iran
}

Received 12 April 2006, Accepted 27 July 2006

Recently, we have reported that 3-hydrogenkwadaphnin (3-HK), a diterpene ester isolated from Dendrostellera lessertii (Thymealeaceae), is very effective against leukemia cell lines without any detectable effects on normal cells (Moosavi et al., 2005b). In this study, we report that 3-HK induces $G_{1}$ cell-cycle arrest, differentiation and apoptosis in APL NB4 cell line. Indeed, the drug between 24 to $96 \mathrm{~h}$ induced 7-65\% growth inhibition of NB4 cells. Cell viability was also decreased by $2-55 \%$ between 24 to 96 h treatments with the drug, respectively. These effects of the drug were also dose-dependent. According to flow cytomtry results, 3-HK (15 $\mathrm{nM})$ induced a significant G1-arrest up to $\mathbf{2 4} \mathrm{h}$ which was consequently followed with appearance of sub- $G_{1}$ peak at 72 to $96 \mathrm{~h}$. Hoechst 33258 staining and DNA fragmentation assays confirmed the occurrence of apoptosis among the treated cells. On the other hand, NBT reducing assay, Wright-Giemsa staining, phagocytic activity and expression of cell surface markers (CD11b and CD14) confirmed that the inhibition of proliferation is associated with differentiation especially toward macrophage-like morphology. Interestingly, 3-HK at 5 and $10 \mathrm{nM}$ enhanced the effects of all-trans retinoic acid (ATRA) in NB4 cells. Based on these results, 3-HK might become an ideal candidate for treatment of APL patients pending full exploration of its biological functions.

Keywords: Apoptosis, Cell-cycle arrest, Dendrostellera lessertii, Differentiation, Leukemia, NB4

\footnotetext{
*To whom correspondence should be addressed.

Tel: 98-21-66956976; Fax: 98-21-66404680

E-mail: yazdan@ibb.ut.ac.ir
}

\section{Introduction}

Myeloid leukemia still remains an unresolved challenge in medical treatments. Most chemotherapeutical drugs used in that respect act through induction of apoptosis (Bruserud and Gjertsen, 2000; Wang, 2003). However, it has been shown that, after treatment with all-trans-retinoic acid (ATRA), remission occurs in patients with acute promyelocytic leukemia (APL) which is a subtype of myeloid leukemia (Honma et al., 1980; Bruserud and Gjertsen, 2000). Apparently, under this situation, the immature hematopoietic cells are led to differentiation toward non-proliferating, more mature granulocytes (Spira and Carducci, 2003). This novel observation has set up the base for differentiation therapy which is presently under considerations as a promising strategy for some of the cancer treatments. Along this line, the differentiation potency of several compounds have been evaluated so far using human APL cell lines (Collins et al., 1978; Rovera et al., 1979; De The et al., 1991; Bhatia et al., 1994; Coco et al., 1998). Some of these compounds such as 12-0-tetradecanoylphorbol-13acetate (TPA) induces monocyte/macrophage differentiation of NB4 cells. However, its clinical application is avoided due to its tumor-promoting activity (Chan and Cripe, 2005). This has led to the investigation of alternative agents like phorbol ester that can induce differentiation of leukemia cells without exhibiting carcinogenic activity.

In that respect, our lab has also characterized a novel daphnane-type diterpene ester (3-hydrogenkwadaphnin, 3HK) from Dendrostellera Lessertii (Thymealeaceae) with potent differentiation and apoptotic activities in several human leukemia cell lines without any adverse effects on normal cells (Yazdanparast and Mianabadi, 2004; Moosavi et al., 2005b). In general, among plant-derived agents, the daphnanetype diterpene esters such as genkwadaphnin (Hall et al., 1982), gnidilatimonoein (Yazdanparast and Sadeghi, 2004), genididin, giniditrin and genidilatin (Stanoeva et al., 2005) possess significant anti-leukemic activity with major metabolic effects on the DNA and protein syntheses. Our further 
investigations have revealed that 3-HK (Scheme 1) inhibits inosine 5'-monophosphate dehydrogenase (IMPDH) activity (Moosavi et al., 2005b). Indeed, IMPDH catalyzes the ratelimiting reaction of de novo guanine nucleotide biosyntheses and alterations in its activity have been implicated in regulation of cellular growth, transformation, differentiation and apoptosis (Jayaram et al., 1999; Inai et al., 2000). In fact, several IMPDH inhibitors such as mycophenolic acid and tiazofurin have been used as chemotherapeutic drugs for leukemia cells (Inai et al., 2000).

More recently, we have shown that $3-\mathrm{HK}$ can induce differentiation as well as apoptosis in HL-60 cells (Yazdanparast et al., 2005). However, its differentiating effects in other human leukemia cell lines especially in NB4 cell line, as an important in vitro APL model, remain to be disclosed. Here, the differentiating activity of $3-\mathrm{HK}$ in NB4 cells, with bileanage differentiation capability under the influence of different drugs, is evaluated.

\section{Materials and Methods}

Materials. The cell culture medium (RPMI 1640), fetal bovine serum (FBS) and penicillin-streptomycin were purchased from Gibco BRL. The culture plates were obtained from Nunc. NB4 cell line was obtained from Pasteur Institute of Iran (Tehran). Propidium iodide (PI), 12-0-tetradecanoylphorbol-13-acetate (TPA), nitroblue tetrazolium (NBT), Wright-Giemsa, all-trans-retinoic acid (ATRA) and Hoechst 33285 were purchased from Sigma. Dimethylsulfoxide (DMSO) was obtained from Merck. Guanosine was purchased from Aldrich Chemical Co. Ltd. Ethidium bromide (EtBr), and RNase were obtained from Pharmacia LKB Biotechnology. 3-HK was isolated in our lab as reported previously (Yazdanparast and Mianabadi, 2004).

Cell culture and the drug treatments. The NB4 cells were cultured in RPMI 1640 medium supplemented with FBS (10\%, v/ v), streptomycin $(100 \mu \mathrm{g} / \mathrm{ml})$ and penicillin $(100 \mathrm{U} / \mathrm{ml})$. 3-HK was dissolved in the medium containing DMSO. Twenty four hours after seeding, the cells were treated with a single dose of the drug with variable concentrations $(5-30 \mathrm{nM})$. In all treatments the DMSO has been kept bellow $0.1 \% \mathrm{v} / \mathrm{v}$.

Cell number and adherence. To examine the effects of 3-HK on cell growth and adherence, $5 \times 10^{4}$ cells $/ \mathrm{ml}$ were seeded in a 24 well-plate. Twenty four hours after seeding, the cells were treated with various concentrations of $3-\mathrm{HK}(5-30 \mathrm{nM})$. At $24 \mathrm{~h}$ intervals, the non-adherent cells were collected and the attached cells were exposed to trypsin- EDTA solution (Song \& Norman, 1998). Both samples (adherent and non-adherent cells) were separately counted using a hemocytometer to determine the percent of the adherent cells. After combining both fractions, aliquots $(100 \mu \mathrm{l})$ were taken to count the cell number and to determine the percent growth inhibition (Song and Norman, 1998).

Cell cycle analysis. DNA content was analyzed on a Partec PAS flow cytometer according to the established procedure (Moosavi et al., 2005b). The cells $\left(5 \times 10^{4}\right.$ cells/well $)$ were seeded into culture dishes $24 \mathrm{~h}$ prior to treatments. The cells were harvested after treatment with $15 \mathrm{nM}$ of 3-HK for various time intervals. The cells were washed twice with PBS, fixed in $70 \%$ ethanol, and kept at $20^{\circ} \mathrm{C}$ until analyses. The cells were then stained with $20 \mu \mathrm{g} / \mathrm{ml}$ propidium iodide containing $20 \mu \mathrm{g} / \mathrm{ml}$ RNase (DNase free) for $2 \mathrm{~h}$. The stained cells were analyzed by flow cytometry. The population of cells distributed among $\mathrm{G}_{0} / \mathrm{G}_{1}, \mathrm{~S}$, and $\mathrm{G}_{2} / \mathrm{M}$ phases were then determined using Cell Cycle Software. The results are expressed as percentage of the cells in each phase.

DNA fragmentation assay. DNA fragmentation in NB4 cells was evaluated by Quick Apoptotic DNA Ladder Detection Kit from Biosource, according to the manufacturer procedure. Briefly, NB4 cells $\left(1 \times 10^{5}\right.$ cells/well $)$ were treated with $15 \mathrm{nM}$ of 3 -HK for various time intervals. The cells were collected and the soluble DNA fragments were extracted from the cells. The extracted DNA fragments were loaded onto a $1.5 \%$ agarose gel containing $0.5 \mu \mathrm{g} /$ $\mathrm{ml}$ ethidium bromide in both gel and the running buffer $(1 \times \mathrm{TBE})$. The gel was run at $5 \mathrm{~V} / \mathrm{cm}$ for 2 hours, then the gel was photographed under UV transillumination.

Morphological evaluation of the apoptotic cells. NB4 cells $\left(5 \times 10^{4}\right.$ cells/well $)$ seeded in 24-well plates and treated with $15 \mathrm{nM}$ of 3-HK for time course of $96 \mathrm{~h}$. Apoptosis was determined morphologically after staining the cells with Hoechst 33258 using fluorescence microscopy. The cells were washed with cold PBS

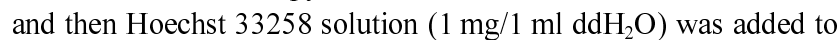
the cell suspension in a final concentration of $100 \mu \mathrm{g} / \mathrm{ml}$. The cellular morphology was evaluated by Axoscope 2 plus fluorescence microscopy (Zeiss).

Morphological evaluation of differentiation. The morphologies of untreated and drug-treated cells were studied during a time course of $96 \mathrm{~h}$ using phase-contrast microscopy (Zeiss). For a more detailed inspection of monocytic differentiation criteria, the cells were harvested, stained with Wrigh-Giemsa solution and studied with a light microscope.

NBT reducing assay. NB4 cells $\left(2.5 \times 10^{5}\right.$ cells $/ 60 \mathrm{~mm}$ dish $)$ were cultured in the presence of different concentrations of $3-\mathrm{HK}$, in RPMI-1640 medium containing 10\% FBS for various time intervals (1-4 days). After harvesting the attached and unattached cells, NBT reducing activity was determined (Song and Norman, 1998; Yazdanparast et al., 2005). The cells were suspended in 100 $\mu \mathrm{l}$ of NBT solution $(4 \mathrm{mg} / \mathrm{ml})$. After addition of $100 \mu \mathrm{l}$ of TPA solution $(2 \mu \mathrm{g} / \mathrm{ml})$, the cell samples were incubated at $37^{\circ} \mathrm{C}$ for 30 min. The differentiated cells were identified by their intracellular blue formazan deposits. A minimum of 400 cells has been counted, using a light microscope, to determine the percent of differentiated cells.

Latex particle phagocytosis assay. NB4 cells $\left(5 \times 10^{4}\right.$ cells/well $)$ were treated with $15 \mathrm{nM} 3-\mathrm{HK}$ for $72 \mathrm{~h}$ in a $24-w e l l$ plate. Then, the control and the treated cells were assayed for their ability to phagocytize protein coated latex particles (Yazdanparast et al., 2005). A protein-coated latex particle suspension commercially available for pregnancy test (Ortho gravindex) was used for this 

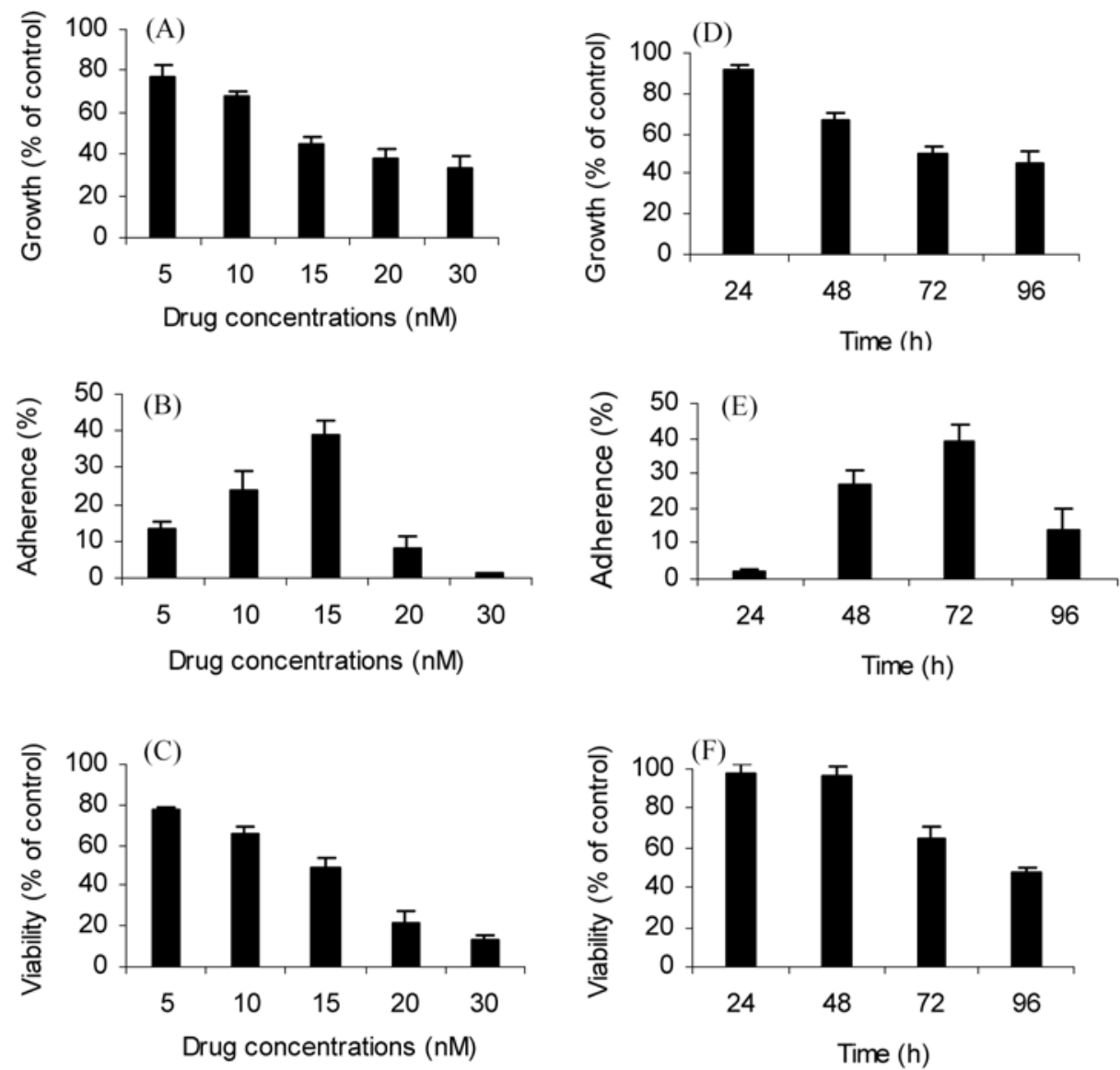

Fig. 1. Dose- and time-dependent effects of $3-\mathrm{HK}$ on growth, viability and adherence of NB4 cells. The cells were treated with different concentrations of 3-HK for 72 or $96 \mathrm{~h}$. Dose-dependent effects of the drug, after $96 \mathrm{~h}$, on growth (\% of control), and viability ( $\%$ of control) are presented in A and C, respectively. Dose-dependent effects of the drug, after $72 \mathrm{~h}$, on adherence (\% of total cells) is also presented in B. Time-dependent effects of $15 \mathrm{nM} 3-\mathrm{HK}$ on growth (D), adherence (E) and viability (F) were also determined. The results are the means of three independent experiments $\pm \mathrm{SD}(p<0.05)$.

assay. The particle suspension was diluted $1: 10$ with PBS and the diluted suspension $(100 \mu \mathrm{l})$ was mixed with $10^{5}$ cells in $100 \mu \mathrm{l}$ RPMI-1640 supplemented with $20 \%$ FBS. The mixture was incubated for $2 \mathrm{~h}$. Then the cells were washed 3 times with cold PBS and resuspended in PBS. A minimum of 200 cells were counted using a light microscope. Cells, with a minimum of ten ingested particles, were considered positive.

Flow cytometric assessment of differentiation. The expression of differentiation markers of CD14 and CD11b were determined by flow cytomerty (Partec Pas). The cells were harvested at indicated times, washed twice with PBS, then incubated for $30 \mathrm{~min}$ at room temperature with $10 \mu \mathrm{l}$ mouse anti-human phycoerythrin (PE)conjugated CD14 mAb (IQproduct) and mouse anti-human fluorescein isothiocyanate (FITC)-conjugated CD11b mAb (IQproduct). Two parameter analyses were performed using flow cytometry (Inai et al., 2000). Mouse isotypes matching IgGs, were used to set threshold parameters for flow cytometry.

\section{Results}

Effects of 3-HK on growth and viability of NB4 cells. The anti-proliferative effect of $3-\mathrm{HK}$ at $5-30 \mathrm{nM}$ was established by measuring the total number of cells in each treated well. As shown in Fig. 1A, the drug at $5-30 \mathrm{nM}$ concentrations inhibited NB4 proliferation by $33-77 \%$ after 4 days of treatment. In addition, 3-HK affected proliferation of the treated NB4 cells in a time-dependent manner when a fixed dose of 3-HK (15 nM) was used (Fig. 1B). For example, the proliferation was inhibited by almost $50 \%$ after 3 days of treatment by $15 \mathrm{nM} 3-\mathrm{HK}$ (Fig. 1B). A time- and dosedependent increase in the number of adherent cells was also detected after 3-HK treatment. Indeed, in control NB4 cells, vehicle alone had no effect on cell adherence, whereas a timedependent increase in the number of adherent cells was observed after treatment with $15 \mathrm{nM}$ 3-HK (Fig. 1, B and E). Viability was also tested by trypan blue assay. Based on the 


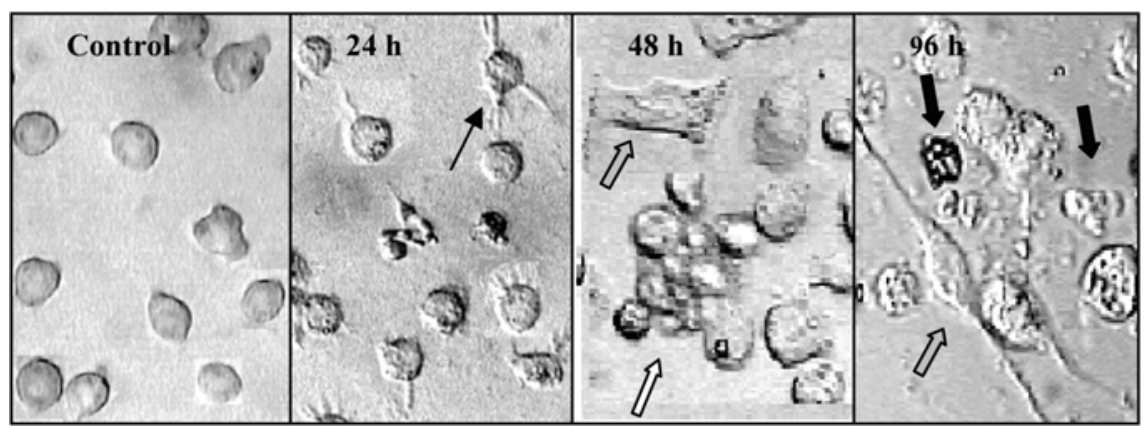

Fig. 2. Effects of 3-HK on morphology of NB4 cells. The cells were treated with $15 \mathrm{nM} 3-\mathrm{HK}$ for $24-96 \mathrm{~h}$. After $20-24 \mathrm{~h}$ of treatment, the pseudopodia were detected on the surface of some of the treated cells ( $24 \mathrm{~h}$, narrow arrow). At $48 \mathrm{~h}$, the cell-to-cell adherence (white arrow) and cell-to-plate adherence (gray arrow) were observed. Adherent cells underwent a fine process which resulted in long pseudopodia ( $96 \mathrm{~h}$, gray arrow). Some of the treated cells died after $96 \mathrm{~h}$ treatment (black arrows). Magnification: 400×.

(A)

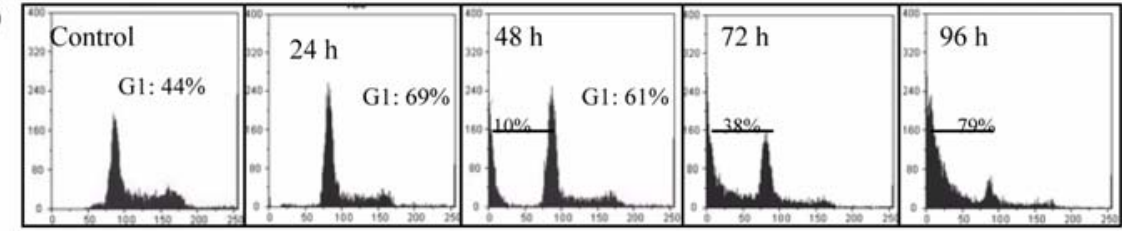

(B)
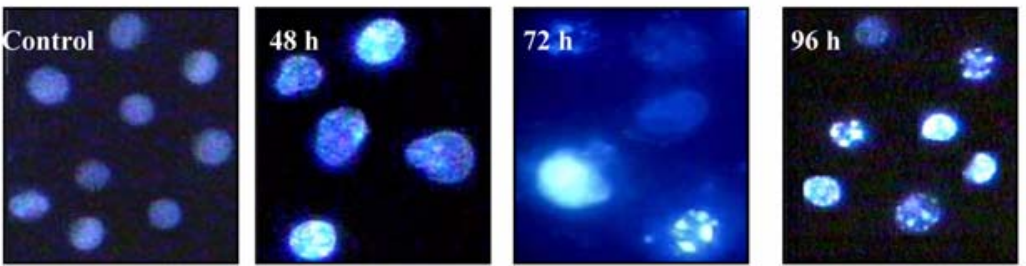

(C)

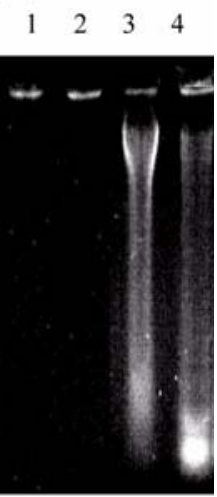

Fig. 3. Effects of 3-HK on cell cycle and apoptosis of NB4 cells. The cells were treated with $15 \mathrm{nM} 3-\mathrm{HK}$ for different times, then the cell cycle pattern (A), morphological studies of nuclei (B) and DNA electrophoresis (C) were studied. C: DNA fragmentation in untreated (Lane 1) NB4 cells and after treatment with $15 \mathrm{nM}$ 3-HK for $24 \mathrm{~h}$ (Lane 2), 48 (Lane 3) and $96 \mathrm{~h}$ (Lane 4).

data presented in Fig. 1 (C and F) the inhibition of proliferation could be attributed to reduction in viable cell numbers at long treatment times or at high drug concentrations. According to our previous observations (Yazdanparast et al., 2005), 3-HK, at high concentrations, had cytotoxic effects on different cultured neoplastic cell lines. Additionally, we observed that at concentrations above $\operatorname{IC}_{50}(>15 \mathrm{nM})$, the viability of NB4 cells decreased sharply with a maximum cell death detected after 24-48 h (data not shown).

Morphological study of NB4 cells after treatment with 3HK. Treatment of NB4 cells with the drug caused adherence of the cells to the culture plates and/or to each other leading to aggregate formation. The variation in cell-to-cell adherence during $96 \mathrm{~h}$ of drug exposure is shown in Fig. 2. Twenty four hour after exposure to $3-\mathrm{HK}$, some of the cells were attached to the culture plates. Cell-to-cell adherence occurred between 48-72 h of drug exposure. However, some cells were dead after 2-4 days of the drug exposure (Fig. 2, $96 \mathrm{~h}$ ). These morphological changes seem very similar to effects of another diterpene ester (TPA) on inducing monocyte/macrophage differentiation of leukemia cell lines (Koeffler et al., 1981).

3-HK induced G1 cell cycle arrest and apoptosis in NB4 cells. Due to profound effects on growth and viability of NB4 cells, we studied 3-HK effects on progression of the cell cycle, too. As shown in Fig. 3A, an increase in $\mathrm{G}_{1}$ cell population was observed after treatment of the cells with $15 \mathrm{nM} 3-\mathrm{HK}$. Indeed, $\mathrm{G}_{1}$ cell cycle arrest was observed after $24 \mathrm{~h}$. Interestingly, sub- $\mathrm{G}_{1}$ peaks (representing apoptosis) were registered after the drug exposure time of 48, 72 and $96 \mathrm{~h}$. These observations are in agreement with the previous results (Fig. 2). Staining with Hoechst 33258 clearly documented the occurrence of apoptosis in NB4 cells after 2, 3 and 4 days of drug exposure, but not at shorter exposure times (Fig. 3B). In Fig. 3B, viable cells are uniformly blue, whereas apoptotic cells are blue and contain bright blue dots in their nuclei as a consequence of chromatin condensation and nuclear fragmentation. In addition, the DNA laddering patterns were also documented among the cells treated with 3-HK for 3-4 days (Fig. 3C, Lane 3 and 4). These results clearly show that $3-\mathrm{HK}$ induced post- $\mathrm{G}_{1}$ arrest apoptosis in NB4 cells. 

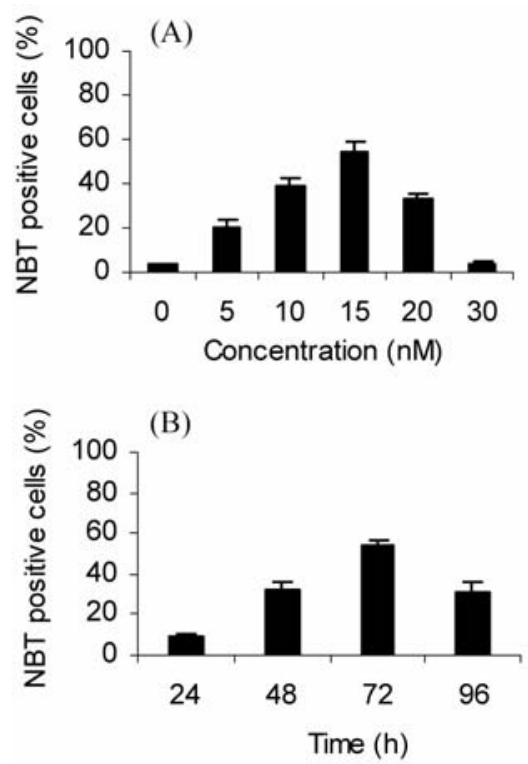

(C)

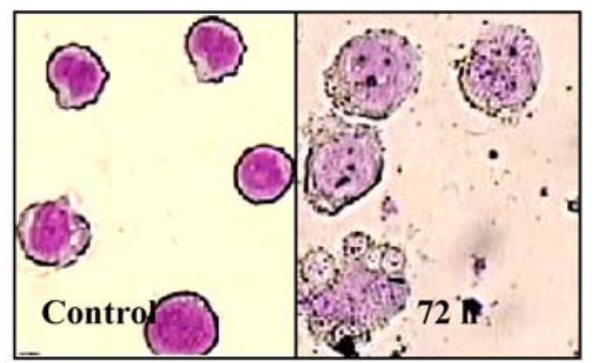

(D)

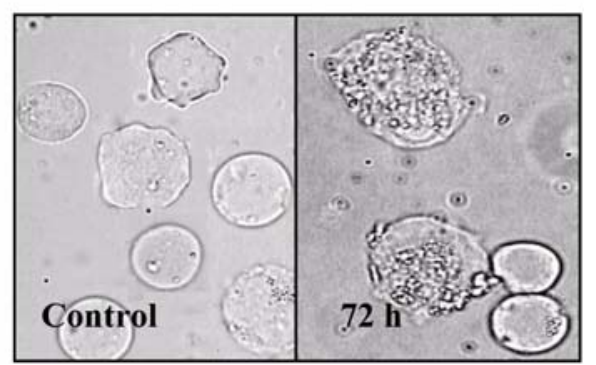

Fig. 4. Effect of 3-HK on differentiation of NB4 cells. The differentiating effect of the drug was evaluated by NBT reduction assay (a and b), Wright-Giemsa staining (c) and phagocytic activity (d) in NB4 cells. a: percentage of NBT reducing cells after treatments with different concentrations of 3-HK for $72 \mathrm{~h}$. b: percentage of NBT reducing cells after treatment with $15 \mathrm{nM}$ of 3 -HK for different times. The results are the means of three independent experiments \pm SD. In $\mathrm{c}$ and $\mathrm{d}$ the cells were treated with $15 \mathrm{nM} 3-\mathrm{HK}$ for $72 \mathrm{~h}$, then the differentiation criteria were studied by Wright-Giemsa staining (c) and the phagocytic activities (d) were evaluated by the ingestion of latex particles. Magnification: 400x.

\section{3-HK induced monocyte/macrophage differentiation of} NB4 cells. In order to clarify whether the inhibitory effects of 3 -HK on the growth and cell cycle of NB4 cells are followed by differentiation, we subjected the 3-HK-treated cells to NBT assay which is a reliable marker for differentiation of myeloid leukemia cells. Fig. 4a clearly indicates that $3-\mathrm{HK}$ is capable of inducing differentiation in NB4 cells in a dose-dependent manner. After $72 \mathrm{~h}$ of incubation with $5-15 \mathrm{nM}$ of the drug, the percent of NBT reducing cells rose from $9 \%$ to $54 \%$. The level of differentiation among untreated cells remained low (3-4\%) after 3-4 days. The time course of differentiation in NB4 cells, subjected to $15 \mathrm{nM}$ of the drug, was also studied. As shown in Fig. 4b, NBT reducing activity was observed $24 \mathrm{~h}$ after drug treatment and reached to a maximum level after $72 \mathrm{~h}$.

To further document the events of differentiation, WrightGiemsa staining was also performed using the treated NB4 cells. As showed in Fig. 4c, morphological features of monocytic differentiation, such as condensation of nuclei and protrusion of cytoplasms, were clearly evident among the treated cells.

Phagocytoses of the latex particles, which is frequently considered as a criterion of proper function of mature macrophages, showed that human promyelocytic leukemia cells have been differentiated into cells having the characteristics of macrophages (Koeffler et al., 1981; Yazdanparast et al., $2005)$. For example, $37.2 \pm 4.3 \%(n=4 ; p<0.05)$ of the treated NB4 cells were able to take the latex particles after $72 \mathrm{~h}$ of treatment with $15 \mathrm{nM}$ of the drug. (Fig. 4d). However, under the same experimental conditions, $2-4 \%$ of the control cells were able to ingest a minimum of ten particles.

In addition, flow cytometric analyses of the treated cells clearly indicated the high expression of CD11b and CD14 markers on the cell surfaces (Fig. 5). Indeed, CD11b expression is taken as the marker for granulocytic and monocytic differentiation, while CD14 expression is considered as the specific marker for monocytic differentiation. Compared to the untreated cells, the population of CD11b- and CD14positive cells increased by almost $61 \%$ and $21 \%$, respectively, among the drug treated cells. These results clearly confirm the differentiation of NB4 cells upon 3-HK treatments along monocyte/macrophage lineage.

3-HK enhanced ATRA-induced differentiation of NB4 cells. In this investigation the modulation of differentiation potency of ATRA by $3-\mathrm{HK}$ was also evaluated. According to results presented in Table 1, ATRA (at $10 \mathrm{nM}$ ) is capable of causing differentiation in NB4 cells by almost $42 \%$. However, the extent of differentiation by ATRA increased to $79 \%$ and $61 \%$ in the presence of 5 and $10 \mathrm{nM} 3-\mathrm{HK}$, respectively. Higher concentrations of $3-\mathrm{HK}$ seemed less active probably due to its cytotoxic effects. Flow cytometric analyses (Fig. 5) also indicated that an increase in population of CD11b-positive cells occurred after exposure of NB4 cells to combination of 3 -HK and ATRA (78\%) compared to ATRA alone (40\%).

Guanosine antagonized 3-HK effects on NB4 cells. Based on our previous findings, 3-HK modulates the guanine nucleotide pool size of the treated HL-60 and K562 cells (Moosavi et al., 


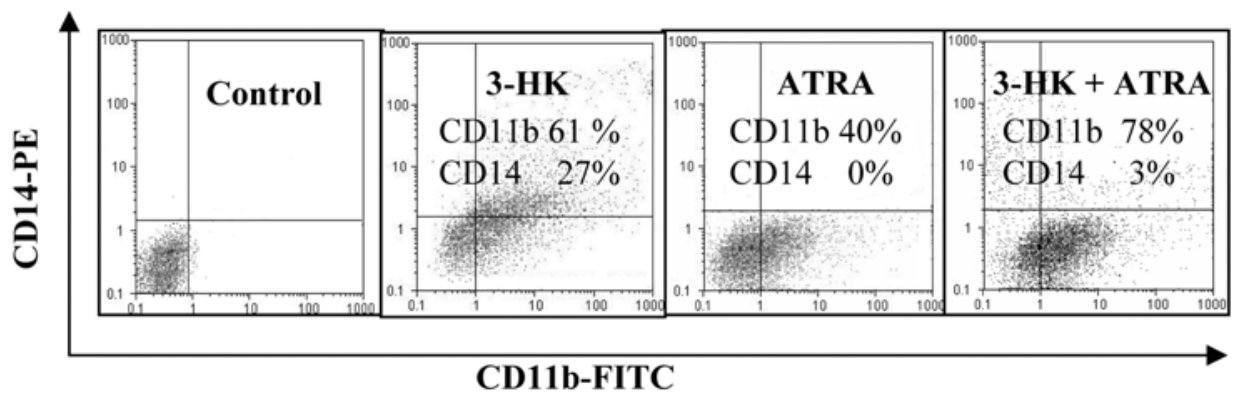

Fig. 5. Effects of 3-HK and ATRA on differentiation markers (CD11b and CD14) in NB4 cells. The NB4 cells were treated with 3-HK $(10 \mathrm{nM})$, ATRA $(10 \mathrm{nM})$ and/or simultaneously with 3-HK $(10 \mathrm{nM})$ and ATRA $(10 \mathrm{nM})$ for $96 \mathrm{~h}$. Expression of cell-surface markers (CD11b and CD14) in the drug-treated cells were evaluated by flow cytometry as mentioned in materials and methods. Total percent of positive cells (CD14: two upper quadrants; CD11b: two right-side quadrants) are indicated in each panel.

2005a). To disclose the mode of action of 3-HK in NB4 cells, we studied the involvement of guanine nucleotide in proliferation and differentiation induced by the drug. In that respect, the cells were simultaneously treated with $50 \mu \mathrm{M}$ guanosine and $15 \mathrm{nM}$ of 3-HK. As shown in Table 2, the antiproliferative and differentiating activities of 3-HK were both quenched in the presence of guanosine. These results reveal that the decrease in GTP pool size, probably through inhibition of IMPDH activity, might be one of the ways that 3HK exerts its biological effects.

Table 1. Combined effects of ATRA and 3-HK on differentiation of NB4 cells. $3-\mathrm{HK}$ at 5 and $10 \mathrm{nM}$ was added alone or in combination with ATRA $(10 \mathrm{nM})$. Differentiation and growth inhibition were assessed after $96 \mathrm{~h}$ by counting the NBT-positive cells and the cell numbers, respectively. The results are the means of three independent experiments $\pm \mathrm{SD}(p<0.05)$

\begin{tabular}{cccrc}
\hline $\begin{array}{c}3-\mathrm{HK} \\
(5 \mathrm{nM})\end{array}$ & $\begin{array}{c}\text { ATRA } \\
(10 \mathrm{nM})\end{array}$ & $\begin{array}{c}3-\mathrm{HK} \\
(10 \mathrm{nM})\end{array}$ & $\begin{array}{c}\text { Differentiation } \\
(\%)\end{array}$ & $\begin{array}{c}\text { viability } \\
(\% \text { of control })\end{array}$ \\
\hline- & - & - & $3 \pm 1.9 \%$ & $100 \%$ \\
- & - & + & $39 \pm 2.9 \%$ & $65 \pm 4.3 \%$ \\
+ & - & - & $19 \pm 4.2 \%$ & $77 \pm 2.1 \%$ \\
- & + & - & $42 \pm 3.1 \%$ & $63 \pm 3.7 \%$ \\
- & + & + & $61 \pm 1.8 \%$ & $52 \pm 2.5 \%$ \\
+ & + & - & $79 \pm 2.7 \%$ & $68 \pm 4.3 \%$ \\
\hline
\end{tabular}

Table 2. The effect of guanosine on the induction of NB4 differentiation and proliferation. The cells were treated with 15 $\mathrm{nM} 3-\mathrm{HK}$ in the presence or absence of $50 \mu \mathrm{M}$ guanosine for $96 \mathrm{~h}$. Differentiation was assessed by NBT reducing assay. The results are the means of three independent experiments $\pm \mathrm{SD}$ $(p<0.05)$

\begin{tabular}{cccc}
\hline $\begin{array}{c}\text { Guanosine } \\
(50 \mu \mathrm{M})\end{array}$ & $\begin{array}{c}\text { Drug } \\
(15 \mathrm{nM})\end{array}$ & $\begin{array}{c}\text { NBT reducing } \\
(\%)\end{array}$ & $\begin{array}{c}\text { Viability } \\
(\% \text { of control })\end{array}$ \\
\hline- & - & $4 \pm 1.1 \%$ & $100 \%$ \\
+ & - & $14 \pm 2.3 \%$ & $104 \pm 2.2 \%$ \\
- & + & $46 \pm 3.3 \%$ & $50 \pm 3.6 \%$ \\
+ & + & $24 \pm 4.2 \%$ & $77 \pm 4.1 \%$ \\
\hline
\end{tabular}

\section{Discussion}

Several leukemia diseases are characterized by breakdown in their cell maturation pathways. To assist the restoration of normal pathways, some patients are treated with differentiating agents like ATRA. Many of these therapeutic agents, however, have short lifes and are accompanied by a variety of side effects, such as drug-resistance and hypercalcemia (Honma et al., 1980; Spira. and Carducci, 2003). Therefore, it is worthwhile to search for new substances which induce differentiation alone or in combination with the established inducers of differentiation.

In that respect, we found that $3-\mathrm{HK}$, a new plant-derived agent, is capable of inducing $\mathrm{G}_{1}$ cell cycle arrest, differentiation, and apoptosis in NB4 cells. Indeed, the lack of tumorpromoting activity makes $3-\mathrm{HK}$ a probable candidate for leukemia therapy. NBT reducing assay (Fig. 4), adherence to the culture plates (Fig. 2), Wright-Giemsa staining (Fig. 4c), phagocytic activity (Fig. 4d) and expression of differentiation cell surface markers (Fig. 5) all show that the drug at low concentrations $(5-15 \mathrm{nM})$ is a potent inducer of differentiation in NB4 cells toward macrophage lineage. Similar to NB4 cells, we have reported that HL-60 cells were also differentiated into monocyte/macrophages by 3-HK, although to a lesser extent (Yazdanparast et al., 2005). This is probably due to the fact that HL-60 cells are in a less mature stage than NB4 cells on the myeloid cell differentiation pathway (Song and Norman, 1998). Indeed, and according to an FAB (FrenchAmerican-British) classification, HL-60 cells are considered as an AML-M2 subtype whereas NB4 cells are a typical cell line belonging to AML-M3 subgroup.

Flow cytometric analyses indicated that the drug-treated NB4 cells underwent $\mathrm{G}_{1}$ arrest after $24 \mathrm{~h}$ of drug treatment. However, sub- $\mathrm{G}_{1}$ peaks were recorded $48-96 \mathrm{~h}$ after treatment with $15 \mathrm{nM} 3-\mathrm{HK}$. These results were confirmed by morphological (Hoechst staining) and biochemical (DNA fragmentation) studies, suggesting that apoptosis was initiated after $\mathrm{G}_{1}$ arrest $(24 \mathrm{~h}$ ) with a maximum effect at $96 \mathrm{~h}$. This is consistent with our previous report concerning the effects of 
3-HK on K562 and HL-60 cells, where a post $\mathrm{G}_{1}$-arrest apoptosis was observed after the drug-treatment (Moosavi et al., 2005b). It has been reported that apoptosis is a major physiological mechanism of cell death in terminally differentiated hematopoietic cells. For example, apoptosis plays an important role in the elimination of activated granulocytes and monocytes (Martin et al., 1990). This is probably because the mature blood cells have short life spans both in vitro and in vivo and, therefore, die as a result of apoptosis (Watson et al., 1997). Apparently, at low concentrations, the drug shows differentiation activity and the differentiated cells are then removed by apoptosis. We also observed that the NB4 cells did not differentiate at the drug concentrations above $20 \mu \mathrm{M}$. This is mostly due to the cytotoxic effects of the drug at high doses.

Moreover, the drug is capable of increasing the ATRAinduced differentiation in NB4 cells. A similar observation has been observed by Danilenko and colleagues who showed that the inducer of monocyte/macrophage differentiation (carnosic acid) was capable of enhancing the efficiency of ATRA (Danilenko et al., 2001). Thus, it appears that ATRAinduced granulocytic differentiation involves signaling circuits similar to those that are active in monocytic differentiation. Nevertheless, such low-dose combination therapies may assist to avoid the acute side effects of ATRA in APL therapies (Kim et al., 2004).

Our date also showed that guanosine (at $50 \mu \mathrm{M}$ ) is capable of preventing the differentiation and apoptosis of NB4 cells treated with 3-HK. This may indicate that the drug exerts its growth inhibiting and differentiating effects through depletion of guanine nucleotide pool size in the treated cells. In fact, inhibition of IMPDH activity by 3-HK, supports this view (Moosavi et al., 2005; Yazdanparast et al., 2005). Modulation of guanine nucleotide pool size by 3-HK may affect pathways which are involved in differentiation and apoptosis. Further work is in progress to respond to some of these possibilities.

In conclusion, the present data indicate that 3-HK, through unknown mechanism(s), induces differentiation and apoptosis in human promyelocytic NB4 leukemia cells. Therefore, this new natural product alone or probably in combination with other differentiation inducers, especially ATRA, may be used as a powerful candidate for leukemia therapy.

Acknowledgments The authors appreciate the joint financial support of this investigation by the research council of the University of Tehran and the National Research Center for Genetic Engineering and Biotechnology, Tehran, Iran.

\section{References}

Bhatia, M., Kirkland, J. B. and Meckling-Gill, K. A. (1994) MCSF and 1,25 dihydroxy vitamin D3 synergize with 12-Otetradecanoylphorbol-13-acetate to induce macrophage differentiation in acute promyelocytic leukemia NB4 cells.
Leukemia 8, 1744-1749.

Bruserud, O. and Gjertsen, B. T. (2000) New strategies for the treatment of acute myelogenous leukemia: differentiation induction-present use and future possibilities. Stem Cells. 18, 157-165.

Chang, R. J. and Cripe, L. D. (2005) 12-O-Tetradecanoylphorbol13-acetate in acute myeloid leukemia. Leuk Res. 29, 1107-1108.

Collins, S. J., Ruscetti, F. W., Gallagher, R. E. and Gallo, R. C. (1978). Terminal differentiation of human promyelocytic leukemia cells induced by dimethylsulfoxide and other polar compounds. Proc. Natl. Acad. Sci. USA 75, 2458-2462.

Coco, F. L., Nervi, C., Avvisati, G. and Mandelli, F. (1998) Acute promyelocytic leukemia: a curable disease. Leukemia 12, 18661880.

Danilenko, M., Wang, X. and Studzinski, G. P. (2001) Carnosic acid and promotion of monocytic differentiation of HL60-G cells initiated by other agents. J. Nat. Cancer Inst. 93, 12241233.

De The, H., Lavau, C., Marchio, A., Chomienne, C., Degoes, L. and Dejean, A. (1991) The PML-RAR alpha fusion mRNA generated by the $\mathrm{t}(15 ; 17)$ translocation in acute promyelocytic leukemia encodes a functionally altered RAR. Cell 66, 675681.

Hall, I. H., Kasai, R., Wu, R. Y., Tagahara, K. and Lee, K. H. (1982) Antitumor agents LV: Effects of genkwadaphnin and yuanhuacine on nucleic acid synthesis of P-338 lymphocytic leukemia cells. J. Pharm. Sci. 71, 1263-1267.

Honma, Y., Takenage, K., Kasukabe, T. and Hozumi, M. (1980) Induction of differentiation of cultured human promyelocytic leukemia cells by retinoids. Biochem. Biophys. Res. Commun., 95, 507-519.

Inai, K., Tsutani, H., Yamauchi, T., Fukushima, T., Iwasaki, H., Imamura, S., Wano, Y., Nemato, Y., Naiki, H. and Ueda, T. (2000) Differentiation induction in non-lymphocytic leukemia cells upon treatment with mycophenolate mofetil. Leuk Res., 24, 761-768.

Jayaram, H. N., Cooney, D. A., Grusch, M. and Krupitza, G. (1999) Consequences of IMP dehydrogenase inhibition, and its relationship to cancer and apoptosis. Curr. Med. Chem. 6, 561574.

Kim, I. S., Jin, J. Y., Lee, I. H. and Park, S. J. (2004). Auranofin induces apoptosis and when combined with retinoic acid enhances differentiation of acute promyelocytic leukaemia cells in vitro. Br. J. Pharmacol. 42, 749-755.

Koeffler, H. P., Bar-Eli, M. and Territo, M. C. (1981) Phorbol ester effect on differentiation of human myeloid leukemia cell lines blocked at different stages of maturation. Cancer Res. 41, 919-926.

Martin, S. J., Bradleyi, J. G. and Cotter, T. G. (1990) HL-60 cells induced to differentiate towards neutrophils subsequently die via apoptosis. Clin. Exp. Immunol. 79, 448-453.

Moosavi, M., Yazdanparast, R. and Sanati, M. H. (2005a) The cytotoxic and anti-proliferative effects of 3-hydrogenkwadaphnin was reduced by guanosine in K562 and Jurkat cells. $J$. Biochem. Mol. Biol. 31, 391-398.

Moosavi, M., Yazdanparast, R. Sanati, M. H. and Nejad, A. S. (2005b) 3-hydrogenkwadaphnin targets inosine 5'monophosphate dehydrogenase and triggers post-G1 arrest apoptosis in human leukemia cell lines. Int. J. Biochem. Cell Biol. 37, 2366-2379. 
Rovera, G., Santoli, D. and Damsky, C. (1979) Human promyelocytic leukemia cells in culture differentiate into macrophage-like cells when treated with a phorbol diester. Proc. Natl. Acad. Sci. USA. 76, 2779-2783.

Song, X. and Norman, A. W. (1998) 1Alpha,25-dihydroxyvitamin D3 and phorbol ester mediate the expression of alkaline phosphatase in NB4 acute promyelocytic leukemia cells. Leuk Re. 22, 69-76.

Spira, A. L. and Carducci, M. A. (2003) Differentiation therapy. Curr. Opin. Pharmacol. 3, 338-436.

Stanoeva, E., He, W. and De Kimpe, N. (2005) Natural and synthetic cage compounds incorporating the 2,9,10-trioxatricyclo [4.3.1.03,8]decane type moiety. Bioorg. Med. Che. 13, 17-28.

Wang, Z. Y. (2003) Ham-Wasserman lecture: treatment of acute leukemia by inducing differentiation therapy and apoptosis.
Hematology (Am Soc Hematol Edu Program., 1-13.

Watson, R. W., Rotstein, O. D., Parodo, J., BitarI, R., Hackam D. and Marshall, J. C. (1997) Granulocytic differentiation of HL60 cells results in spontaneous apoptosis mediated by increased caspase expression. FEBS Lett. 412, 603-609.

Yazdanparast, R. and Mianabadi, M. (2004) The effect of active component of Dendrostellera lessertii on the adhesive property of human platelets and HL-60 cells. Life Sci. 75, 733-739.

Yazdanparast, R. and Sadeghi, H. (2004) Nucleic acid synthesis in cancerous cells under the effect of gnidilatimonoein from Daphne mucronata. Life Sci., 74, 1869-1876.

Yazdanparast, R., Moosavi, M. A., Mahdavi, M. and Sanati, M. H. (2005) 3-hydrogenkwadaphnin from Dendrostellera lessertii induces differentiation and apoptosis in HL-60 cells. Planta Med. 71, 1112-1117. 